\title{
Mucosal colonic defect post EMR or ESD: to close or not?
}

Authors

Institutions
Nicholas G Burgess ${ }^{1,2}$, Michael J Bourke ${ }^{1,2}$

Department of Gastroenterology and Hepatology, Westmead Hospital, Sydney, NSW, Australia

University of Sydney, Sydney, NSW, Australia submitted 19. August 2016 accepted after revision 29. August 2016

\section{Bibliography}

Dol http://dx.doi.org/ 10.1055/s-0042-117220 Endoscopy International Open 2016; 04: E1073-E1074 (c) Georg Thieme Verlag KG Stuttgart · New York E-ISSN 2196-9736

\section{Corresponding author} Prof. Michael J. Bourke, MBBS, FRACP

Clinical Professor of Medicine, Director of Endoscopy Department of Gastroenterology and Hepatology Westmead Hospital c/0 Suite 106a, 151-155 Hawkesbury Road Westmead, Sydney, New South Wales 2143

AUSTRALIA

Phone: +61 298455555

Fax: + 61298455637 michael@citywestgastro.com. au
The advent of endoscopic clips has resulted in a new era in colonic endoscopic resection. Clips provide an easily applicable, durable and robust method of closure of resection defects [1]. This has allowed endoscopists to push the boundaries of techniques with greater control over the risks of perforation and bleeding. Adverse events (AEs) that once may have required surgical salvage can now be managed safely, and provided that a patient's clinical disposition post-endoscopy is unaltered, they are now regarded as procedural events. In the case of per-oral endoscopic myotomy (POEM) and natural orifice transluminal endoscopic surgery (NOTES), clips allow the closure of an iatrogenic full-thickness injury, a concept which was once anathema to endoscopists. There is no question that application of clips is effective in the setting of perforation, mural injury and active bleeding. The ubiquitous availability and ease of use of these devices, however, now may have resulted in the pendulum swinging towards their use in settings where there may be marginal benefit. Endoscopists may use clips to guarantee their peace of mind, rather than according to any evidence-based cost/benefit strategy.

In this edition of Endoscopy International Open, Akimoto et al. describe a novel technique for closure of large colonic endoscopic submucosal dissection (ESD) defects. Repositionable clips are used to grasp the mucosa at the distal defect edge, then drag this into apposition with the proximal defect edge. The clip is then gently opened, allowing capture of the proximal margin while holding the distal margin with one clip arm. The clip is then deployed, holding the defect together so that standard clips may be adjacently applied to the now more closely apposed mucosal edges. The study was a single-center, retrospective cohort of 32 patients undergoing colonic ESD. Clip closure was attempted in 19 patients. Closure was not attempted for rectal lesions $(n=9)$ due to the relative fixation of the colon wall in the pelvis, and was also not attempted where lesions involved the ileocecal valve $(n=3)$ or had evidence of submucosal invasion $(n=1)$. Complete closure was effected in 18/19 patients with 1 failure due to a mobile sigmoid colon. Mean defect size was $40.2 \pm 12.0 \mathrm{~mm}$ and it took a mean $10.7 \pm 7.2 \mathrm{~min}-$ utes to complete the clipping procedure. No adverse events were reported in the clipped group. The authors did not report the frequency of AEs in the unclipped group. The defects do not appear to have been objectively examined prior to clipping to determine if there had been deep injury or perforation. The authors rightly point out that this is a demonstration of concept study, and that it is inadequately powered to determine any effect on adverse outcomes.

In essence, Akimoto et al. have shown us a neat technique with a specialized clip to close large ESD defects. Many who use clips will be familiar with a version of this method using standard clips whereby one arm of an open clip is embedded in a defect edge and dragged by traction to a more favorable position, however, the Akimoto technique allows greater tension and control to be applied. Alternative methods of closure including endoscopic suturing or over-the-scope clips have been described, however, they typically are cumbersome or technically challenging, and require withdrawal and reinsertion of the endoscope. The wider question surrounding these technical tricks is whether we should be closing these resection defects at all.

The benefits of partial or complete closure of EMR or ESD defects are far from certain. There are wellestablished data showing that the rate of clinically significant delayed bleeding is $6 \%$ to $7 \%$ following EMR and $1 \%$ to $2 \%$ following ESD $[2,3]$. Perforation is a rare event for either procedure, occurring in $0.9 \%$ to $2.0 \%$ following EMR and $4 \%$ to $6 \%$ following ESD $[3,4]$. Delayed perforation is even less common, seen in only $0.2 \%$ following EMR [5[. With low event rates, studies examining the effi- 
cacy of clips have to be very large and well designed to demonstrate an effect and exclude bias. Liaquat et al.[6] described delayed bleeding outcomes in a cohort comparing complete clipping of EMR defects to a historical unclipped control group. Defects that could not be clipped were also analyzed together with the historical group.The delayed hemorrhage rate was $9.7 \%$ in the unclipped group versus $1.8 \%$ in the fully clipped group. Multivariate analysis showed that not clipping (odds ratio [OR] 6.0; 95 $\% \mathrm{CI}, 2.0-18.5$ ), location proximal to the splenic flexure (OR 2.9; $95 \% \mathrm{CI}, 1.05-8.1$ ), and polyp size (OR 1.3 ; $95 \% \mathrm{CI}, 1.1-1.7$ for each $10-\mathrm{mm}$ increase in size) were associated with delayed bleeding. Although this study produced an impressive reduction in bleeding rates, the authors acknowledge that it was observational, retrospective and a single-operator study. Methodological issues may have also overestimated the clipping effect $[7,8]$.

Randomized controlled trials to date have been underpowered or contained flaws limiting their applicability to clinical practice [911]. A cost-effectiveness analysis showed that treatment was only potentially viable for lesions $>10 \mathrm{~mm}$ in patients receiving antiplatelet or anticoagulant agents [12] The difficulty justifying the costs of clips comes down to the fact that post-polypectomy bleeding is relatively uncommon, typically self-limited, and the majority can be managed conservatively without expensive and invasive investigations [2]. An economic model simulating several clipping strategies applied to an actual prospective cohort of 1717 lesions undergoing EMR showed that clipping was not cost effective, and in fact, clip prices would have to fall to $€ 10.35$ each in order to offset the cost of delayed bleeding [13]. Selection of cases at highest risk for bleeding may be a feasible way of reducing the numbers needed to treat [14], however, no study has prospectively demonstrated the efficacy of a targeted clipping strategy.

Prophylactic clipping to prevent delayed perforation is devoid of evidence, as the incidence of this often serious $\mathrm{AE}$ is thankfully very low. Any randomized study designed to demonstrate perfect prevention of delayed perforation (ie. risk reduction from an estimate of $0.5 \%$ to $0 \%$ ) would still require at least 1500 patients in each arm. No existing study or research network has approached this size.

Although prophylactic clipping is questionable, the situation is completely different when there is objective evidence of perforation or muscularis propria (MP) injury. The "target sign" is a wellrecognized endoscopic marker of MP injury prompting focal clip placement over the area of concern [15]. This only represents part of the spectrum of colonic mural injury, which may range from simple exposure of the MP, to full-thickness perforation. A classification system describing this range of injuries after EMR has been described along with management strategies based on the appearance of the resection defect [5]. Although there is no objective evidence that this reduces late sequelae, this proactive management approach was associated with a delayed perforation rate of only $0.2 \%$ in 802 patients undergoing EMR of large laterally spreading lesions in a tertiary referral setting, mean size $37 \mathrm{~mm}$ (range $20-120 \mathrm{~mm}$ ).

The risks of clip placement in the colon are few, as the majority of the colon is mobile, tethered only by a mesentery, and the colon walls are pliable. Caution should be exercised in situations in the gastrointestinal tract where these conditions do not apply, for example, the relatively fixed descending duodenum where clips may potentially tear the thin comparatively immobile muscle layer [16]. Clips may also complicate assessment of post-resection scars by creating artefactual mucosal nodules that must be carefully examined to distinguish them from recurrent adenoma.
Usually the distinction is clear based on the morphology and surface pattern [17]. It is also possible (but unreported) that clips may "bury" small areas of residual or recurrent adenoma, preventing detection and resection at surveillance colonoscopy and creating a theoretical risk of subsequent delayed adenomatous recurrence or post-colonoscopy cancer.

When clips were first introduced, their extensive impact on endoscopic practice was impossible to fully appreciate. Incremental advances in clip techniques and technology may deliver further evolutions in endoscopy beyond our current expectations. In their current form, clips have revolutionized endoscopy, but we may be expecting more of them than they can deliver. Prophylactic closure of all defects is expensive and not proven. Rather than asking how to close defects, we must first ask the question: Should we?

\section{Competing interests: None}

\section{References}

1 von Renteln D, Schmidt A, Vassiliou MC et al. Endoscopic full-thickness resection and defect closure in the colon. Gastrointest Endosc 2010; 71: $1267-1273$

2 Burgess NG, Metz AJ, Williams SJ et al. Risk Factors for Intraprocedural and Clinically Significant Delayed Bleeding After Wide-field Endoscopic Mucosal Resection of Large Colonic Lesions. Clin Gastroenterol Hepatol 2014; 12: 651-661.e3

3 Repici A, Hassan C, Pessoa DDP et al. Efficacy and safety of endoscopic submucosal dissection for colorectal neoplasia - a systematic review. Endoscopy 2012; 44: 137-147

4 Arezzo A, Passera R, Marchese $N$ et al. Systematic review and meta-analysis of endoscopic submucosal dissection vs endoscopic mucosal resection for colorectal lesions. United Eur Gastroenterol J 2016; 4: $18-29$

5 Burgess NG, Bassan MS, McLeod D et al. Deep mural injury and perforation after colonic endoscopic mucosal resection: a new classification and analysis of risk factors. Gut 2016: Published Online First: 27 July 2016 DOI 10.1136/ gutjnl-2015-309848

6 Liaquat H, Rohn E, Rex DK. Prophylactic clip closure reduced the risk of delayed postpolypectomy hemorrhage: experience in 277 clipped large sessile or flat colorectal lesions and 247 control lesions. Gastrointest Endosc 2013; 77: $401-407$

7 Rex DK. Response. Gastrointest Endosc 2013; 78: 387-388

8 Burgess NG, Bourke MJ, Byth K. Prophylactic clip closure. Gastrointest Endosc 2013; 78: 386-387

9 Shioji K, Suzuki Y, Kobayashi M et al. Prophylactic clip application does not decrease delayed bleeding after colonoscopic polypectomy. Gastrointest Endosc 2003; 57: 691 -694

10 Zhang QS, Han B, Xu JH et al. Clip closure of defect after endoscopic resection in patients with larger colorectal tumors decreased the adverse events. Gastrointest Endosc 2015; 82: 904-909

$11 \mathrm{Pohl} \mathrm{H}$. Clipping after polyp resection: uncertainties of a randomized trial. Gastrointest Endosc 2015; 82: 910-911

12 Parikh ND, Zanocco K, Keswani RN et al. A cost-efficacy decision analysis of prophylactic clip placement after endoscopic removal of large polyps. Clin Gastroenterol Hepatol 2013; 11: 1319-1324

13 Bahin FF, Rasouli KN, Williams SJ et al. Prophylactic clipping for the prevention of bleeding following wide-field endoscopic mucosal resection of laterally spreading colorectal lesions: an economic modeling study. Endoscopy 2016; 48: $754-761$

14 Bahin FF, Rasouli KN, Byth $K$ et al. Prediction of clinically significant bleeding following wide-field endoscopic resection of large sessile and laterally spreading colorectal lesions: a clinical risk score. Am J Gastroenterol 2016; 111: 1115-1122

15 Swan MP, Bourke MJ, Moss A et al. The target sign : an endoscopic marker for the resection of the muscularis propria and potential perforation during colonic endoscopic mucosal resection. Gastrointest Endosc 2011; 73: 79-85

16 Bourke MJ. Endoscopic resection in the duodenum: current limitations and future directions. Endoscopy 2013; 45: 127-132

17 Pellisé M, Desomer L, Burgess NG et al. The influence of clips on scars after EMR: clip artifact. Gastrointest Endosc 2016; 83: 608-616 